\title{
Сельское население Сибири: вернуть людям смысл жизни на земле (полемические заметки)
}

К.А. АНтОнОВ, доктор социологических наук, руководитель исследовательского Центра СИУ РАНХиГС при Президенте РФ, руководитель Новосибирского филиала Фонда развития гражданского общества. В.3. ШУРБЕ, кандидат социологических наук, Сибирский институт международных отношений и регионоведения, Новосибирск

В статье на основе результатов социологических обследований, проведенных в 2014-2015 гг. в Новосибирской области, анализируются проблемы занятости сельского населения в сельхозпроизводстве и других сферах, делается вывод о необходимости новой аграрной политики - предотвращения запустения сел, поддержки фермерства, сельского образа жизни.

Ключевые слова: сельский образ жизни, региональная политика, исход, сельские труженики, современные “отходники», социальная память села

\section{Урбанистический подход селу не подходит}

Многочисленные экспликации понятия «региональная политика» фиксируют внимание на действиях органов власти (государственных и муниципальных), направленных на достижение интересов регионов $[1,2]$, реализацию механизмов политического, экономического и социального их развития [3. С. 15], удовлетворение основных жизненных потребностей всех социальных групп на локальной территории [4. С. 10]. Экономический детерминизм, это детище классического либерализма, утверждает объективный характер зависимости социальных изменений от экономического базиса, что формирует соответствующий набор управленческих решений. Как правило, речь при этом идет о достижении валовых показателей выпуска продукции, но никак не об устойчивом развитии территории и производительных сил. Анализ специфики исторического процесса, когда следующее поколение людей наследует элементы традиций, быта, способы организации материального производства от предыдущих; локальные особенности конкретной территории и повседневного опыта людей, проживающих там, при таком подходе игнорируются.

Сторонники неоклассических подходов в управлении считают социальные, культурные, исторически сложившиеся архетипы 
производными от экономической сферы. Если они не укладываются в рыночную модель развития, то автоматически признаются утратившими эффективность. Так обстоит дело и с вектором региональной политики в сельских территориях: при ее реализации речь идет главным образом об экономической эффективности (техническое перевооружение, создание крупных агрохолдингов, повышение отдачи от гектара земли и т. п.), а сельская территория зачастую выступает синонимом экономической категории - агропромышленное производство. Однако все попытки модернизации агропромышленного комплекса, игнорирующие многомерность исторически сложившихся социальных, культурных и политических факторов, когда производство агропромышленной продукции рассматривается в отрыве от поддержки сельского образа жизни, обречены на провал.

Неэффективность существующих подходов демонстрируют данные таблицы, из которых следует, что при значительном увеличении год от года средств государственной поддержки поголовье скота и урожайность зерновых падают. Никаким влиянием «климатических факторов» это не объяснить, ведь современные технологии производства, управления, логистики и др. способны в значительной мере нивелировать их неблагоприятное воздействие.

Анализ основных показателей развития сельскохозяйственного производства Новосибирской области за 2007-2013 гг.

\begin{tabular}{|l|r|r|r|r|r|r|l|}
\hline \multicolumn{1}{|c|}{ Показатель } & $\mathbf{2 0 0 7}$ & $\mathbf{2 0 0 8}$ & $\mathbf{2 0 0 9}$ & $\mathbf{2 0 1 0}$ & $\mathbf{2 0 1 1}$ & $\mathbf{2 0 1 2}$ & $\mathbf{2 0 1 3}$ \\
\hline Поддержка АПК, млн руб. & 1706,6 & 2768,3 & 2475,0 & 2398,1 & 2743,2 & 3534,1 & 3967,2 \\
\hline $\begin{array}{l}\text { Индекс производства продукции расте-- } \\
\text { ниеводства, \% }\end{array}$ & 123,6 & 100,3 & 112,3 & 78,2 & 111,3 & 63,1 & 143,5 \\
\hline Валовой сбор зерновых культур, тыс. т & 2502,6 & 2567,3 & 3193,2 & 2350,3 & 2503,3 & 1239,5 & 2292,6 \\
\hline Урожайность зерновых культур, ц/га & 15,9 & 15,7 & 18,9 & 15,1 & 15,2 & 9,6 & 15,4 \\
\hline $\begin{array}{l}\text { Индекс производства продукции живот- } \\
\text { новодства, \% }\end{array}$ & 104,9 & 106,2 & 103,9 & 101,2 & 103,5 & 98,3 & 96,5 \\
\hline Численность поголовья КРС, тыс. голов & 628,9 & 595,6 & 564,5 & 551,3 & 552,7 & 522,3 & 494,4 \\
\hline Численность поголовья свиней, тыс. голов & 313,5 & 324,2 & 355,8 & 400,1 & 372,2 & 371,9 & 335,8 \\
\hline Производство молока, тыс. т & 751,8 & 800,9 & 783,7 & 757,1 & 775,3 & 713,1 & 655,6 \\
\hline
\end{tabular}

Источник: [5].

По заключению Контрольно-счетной палаты, при наличии некоторых плюсов (степень износа основных фондов в сельском хозяйстве уменьшилась с 42,0\% в 2007 г. до 39,0\% на начало 2013 г., увеличились расходы на жилищное обеспечение и социальноинженерное обустройство сельских территорий), распределение господдержки сильно концентрировано: 29\% всех выделенных средств из года в год получают чуть более десятка крупных агропромышленных предприятий, расположенных на 16\% сельской территории, на которой проживают 11\% жителей. Такая концентрация плоха не только потому, что лишает шансов на устойчивое развитие остальные территории и проживающее там сельское население, она также несет большие риски, поскольку эпизоотия или внутренние корпоративные проблемы у крупных производителей могут привести к существенным потерям, отражающимся на всей цепочке экономических связей, и в конечном итоге, на социальноэкономическом положении локальной территории.

При этом очевидно, что для организации современного «рыночного» производства сельхозпродукции, позволяющего задействовать весь имеющийся трудовой ресурс и «обустроить» все территории, средств у региона недостаточно, поэтому возникает необходимость в разработке новой концепции региональной политики в сфере АПК. По нашему мнению, для достижения наибольшего эффекта при создании такой концепции надо учитывать не только теоретические основания и статистическую информацию, но и большой массив субъективных оценок, мнений, суждений жителей сельских территорий Новосибирской области.

\section{О соотношении статистического оптимизма}

\section{и пессимистической реальности}

Для начала проанализируем эмпирические данные, полученные авторами в ходе нескольких социологических исследований. Эмпирической (информацуионной) базой для разработки концеепичии послужили данные, полученные в результате следующих исследований.

- Экспертные опросы с целью мониторинга общественно-политической ситуации в муниципальных образованиях Новосибирской области и оценки эффективности деятельности органов местного самоуправления, выполненные по заказу администрации Новосибирской области в 2014 г. (общий объем выборки - 2200 чел. в 490 муниципальных образованиях). Опрашивались эксперты в возрасте от 30 до 60 лет, имеющие опыт взаимодействия с органами местного самоуправления - линейный, взаимодействующий эксперт с использованием метода полуформализованного нарративного интервью. 
- Опрос глав 429 муниципальных образований (телефонный и анкетный опросы, сплошная выборка) «Сельское население Новосибирской области: исход и диссипативность» - 2014-2015 гг.

- Интервью в фокус-группах, проведенные в 2015 г. в 14 сельских поселениях трех районов, с целью выяснения готовности и наличия возможности у жителей к частичному самообеспечению, самозанятости, самоорганизации, организации производственных, кооперационных связей.

Актуальность такого способа получения статистической информации заключается в следующем.

Первое. Население - это подвижный социальный организм. Перепись населения, статистические сводки на определенные даты не позволяют отслеживать качественную динамику. Кроме того, полученные традиционным способом статистические данные отражают количественные характеристики предмета исследования «здесь и сейчас», которые можно сопоставлять со статистическими индикаторами, полученными на отчетный период.

Второе. Устный опрос позволяет получать не только искомую информацию, но и комментарии, обладающие самостоятельной ценностью в оценке и анализе изучаемой предметной области, отражающие качественные характеристики социального объекта, процесса, явления.

Третье. Устный опрос помогает выявлять компетентность представителей исполнительной власти, их отношение к изучаемым проблемам, а также иные социальные качества, например, активную жизненную позицию или социальную апатию и безысходность, стремление изменять ситуацию или констатировать её состояние и т. п.

\section{Трудоспособное население села. Сельские труженики}

Судя по ответам глав муниципальных образований на вопрос: «Сколько человек трудоспособного населения проживает и работает в населенном пункте?», фактическая численность людей трудоспособного возраста в сельских поселениях, то есть людей, которые фактически проживают и работают на территории своего поселения, практически никогда не совпадает с их списочной численностью ${ }^{1}$. Во многих муниципальных образованиях более 50\% зарегистрированных граждан фактически там не живут и не работают, т.е. официальная статистика не отражает реальное положение дел.

Формула расчета: списочно трудоспособное население по данным муниципальных образований минус трудоспособное население, работающее вахтовым методом, минус трудоспособное население проживающее и работающее вне поселения.
Еще драматичнее ситуация с фактической занятостью сельских жителей. Как показали результаты опроса, лишь в 19 из 429 муниципальных образований (4,4\% от общего их числа) в сельском хозяйстве заняты более половины трудоспособного населения (от 50 до 91\%). В 35 муниципальных образованиях $(8,1 \%)$ сельскохозяйственным трудом заняты от 30 до 50\% трудоспособного населения; в 58 (13,5\%) - от 20 до 30\%; в 95 (22\%) от 10 до 20\%, а в 204 муниципальных образованиях - менее 10\% трудоспособного населения являются сельскими тружениками. Это почти половина всех муниципальных образований области! В 44 сельских советах (это 10,2\% от общего их числа) вообще не смогли назвать, сколько человек работает в сельском хозяйстве (это, к слову, прекрасно характеризует качество управления и владение местными органами власти информацией об управляемом объекте).

Наше исследование не выявило зависимости степени занятости трудящихся в аграрном секторе от расстояния до районного или областного центра, близости к железной дороге или федеральной трассе. Так, в двух районах, через которые проходят и железная дорога, и федеральная автотрасса, в сельском хозяйстве занято лишь от 2,1 до 4,2\% трудоспособного населения. Это наименьший показатель среди сельских районов области. Размер сельского поселения также не играет большой роли.

На наш взгляд, решающее значение для развития аграрного производства имеет тот факт, насколько активно проявляют усилия в этом направлении местные органы власти совместно с руководителями сельхозпредприятий различной формы собственности.

Крайне мала и доля трудоспособного населения, занятого фермерским трудом. По данным опросов, больше всего индивидуальных предпринимателей (от 10,2\% до 12,2\% от общей численности трудоспособного населения) в двух сельских советах, от $8,4 \%$ до $5,4 \%$ - также в двух, в среднем же по области к ним относятся всего 1,5\% жителей села трудоспособного возраста.

Приведем высказывание, которое отражает среди прочих проблем одну из основных - утрату населением понимания сельского образа жизни и уклада: «Деревня существует для того, чтобы жили крестьяне, а живут крестьяне за счет личного подсобного скота, а у нас здесь правители наши, которые сидят в нашем 
“белом <местном> доме”, они здесь земли отдают городским для строительства дач. Когда я пришел к ним и попросил, чтобы сын мой здесь же у меня работал в фермерском хозяйстве, дайте участок земли мне, отказали - нету. Но следом за мной уже построилось дач пятнадияать. Те, которые построили дачи, говорят, что воняют твои фермыл. Так это же ферма, мы привыкли жить скотом, а все производное от скота воняет, и начинаются конфликты. СанПиН бьет нас по голове, что мы не имеем право держать в деревне скот. Здесь раньше у нас было голов 60 только коров, сейчас не больше 20» (муж., 40 лет, фермер).

Фермерское хозяйство не находит должной поддержки ни у населения, ни у руководства и не приживается в сибирской деревне. Среди возможных причин - устойчивость традиции коллективного хозяйствования, отсутствие частнособственнических и индивидуалистических амбиций и хозяйского отношения к земле. Возможно, сильная историческая память о том, как крестьян лишали нажитого, привела к нежеланию брать на себя ответственность. Не исключено, что определенную роль играют административные преграды и препоны, вызванные непониманием важности вовлечения незанятого населения в производство сельскохозяйственной продукции.

Но если в муниципальном образовании лишь мизерная часть трудоспособного населения занята крестьянским трудом, который является основой сельского образа жизни и главным экономическим ресурсом создания продовольствия, можно ли такое поселение называть сельским? И чем управляют главы таких муниципальных образований, если в аграрном секторе у них занято менее 1\% трудоспособного населения, а некоторые вообще не могут сказать, сколько человек трудоспособного возраста занято в сельском хозяйстве?

\section{Кто где работает на селе, если не в сельском хозяйстве?}

Каким должно быть оптимальное соотношение трудоспособного населения в различных сферах экономической деятельности, чтобы сохранить сельский уклад жизни и сельскохозяйственное производство и обеспечить продовольственную безопасность региона и страны в целом? Вопрос непростой.

Наше исследование показало, что значительное количество сельских муниципалитетов не могут обеспечить своих жителей рабочими местами на своей территории. В 98 муниципальных образованиях (22\% их общего количества) от 20 до 50\% трудоспособного населения работают в бюджетной сфере, а в шести к «бюджетникам» относится более 50\% населения. Можно предположить, что в этих муниципалитетах должны быть в основном решены проблемы с кадрами в образовании, медицине, культуре и т. п., однако результаты опроса этого не подтверждают.

Приведем одно из типичных высказываний работника бюджетной сферы: «Должна быть создана инфраструктура в населенном пункте: жильё для молодёжи, дороги, места в садиках для детей без очередей, культурный досуг, спортивная база, чтобы в спортзалах было всё, детские площуадки в летнее время. Зимойхоккейные коробки, чтобы люди, кто не может позволить себе покупку, например, коньков, могли бы прийти и взять эти предметы за небольшую плату напрокат (коньки, льюжи). Чтобы было жилищно-коммунальное хозяйство, чтобы люди не переживали, что сегодня тепло, а завтра холодно. Чтобы было всё в порядке с теплотрассой, водоснабжением. Качество воды лучше, чтобы она была не из колонки, а дома. Создать эти условия, и никто из деревни не поедет. В деревне жить лучше. В деревне присутствует уважение к стариим, чего нет в городе. Это оттого, что все друг друга знают, знают родителей друг друга, поэтому и с уважением относятся» (Барабинск, жен.).

При ответе на вопрос о занятости трудоспособного населения «на других производствах» названы лесхозы, промышленные предприятия по добыче и обработке древесины, производству строительных и отделочных материалов, мебели, пластиковых окон, а также, как ни странно, предприятия, занимающчиеся переработкой сельхозпродукции (мельницы, колбасное, кондитерское и хлебобулочное производство, пекарни, маслосырзаводы, молочные комбинаты, комбикормовые и мясозаготовительные комбинаты, производство растительного масла, птицефабрики, льнозавод и т. п.).

Но таким образом получается, что сельские труженики, которые выращивают скот, птицу, зерновые, подсолнечник, рапс, лен и другую сельхозпродукцию, выступают исключительно в роли производителей сырья, «отрываясь» от конечного продукта. Правомерно ли такое разделение при современном состоянии сельского хозяйства? 
При этом примечательно, что опросы сельского населения, социологическое наблюдение в общественных местах на селе показывают: жители большинства поселений часто не видят и не ощуицают результаты собственного труда. Они не потребляют «деревенское» молоко или мясо, а покупают его в магазине. Из товаров местного производства, представленных в местной торговле, могут назвать только хлебобулочные изделия (при этом не знают конкретного производителя). Нередко продукцию, которая производится здесь, проще увидеть в областном центре, чем в местных магазинах, где она практически не продается. И жители говорят: «Мы бы и сами хотели знать, где и кому её продают». Такое отношение к местным производителям и продуктам их деятельности не только демотивирует сельских жителей к работе на местных предприятиях, но и является противодействующим предпринимательству фактором.

Мы отдельно выделили в опросе маятниковую миграцию и отходничество, хотя это феномены одного порядка. Маятниковая миграция - это условное название регулярных (обычно - ежедневных, но иногда «посменных» - «два через два дня», «на рабочую неделю») поездок населения из одного населённого пункта (места жительства) в другой - на работу или учёбу и обратно. Маятниковая миграция является результатом несоответствия размещения производства и расселения людей. В Новосибирской области она сильнее всего развита в муниципальных образованиях, расположенных в 30-40 км от ближайшего районного центра и в 200-300 км от Новосибирска.

Одной из разновидностей трудовой миграции является «отходничество». Принято считать, что отходничество - это «временный уход крестьян в России с мест постоянного жительства в деревнях на заработки в районы развитой промышленности и сельского хозяйства, оно носит возвратный, временный и сезонный (как правило) характер, так как “отходник” всегда возвращается на место постоянного проживания, где осталась семья. Причины - нужда или возможность внеземледельческих заработков» [6, 7].

Согласно полученным статистическим данным, в 41 муниципальном образовании от 50 до 100\% населения трудоспособного возраста живут и работают вне своего поселения, как правило, в городах Новосибирской области или в самом Новосибирске, но также и в других промышленно-развитых регионах.
Приведем выдержки из типичных ответов жителей села (мартапрель 2014 г.): «... У меня муж вахтовым методом работает... Он уезжает на девять месяиев и деньги илет... А что можно здесь, в деревне... Что я тут могу предпринять, если тут вообще никаких перспектив? Тут у нас больше населения женского сидит дома, то есть они вообще не работают, я на полставки работаю, у меня три часа рабочих» (жен., учитель).

«Людям заняться нечем. ...Лет 10-15 на селе работы нет, молодежь и люди среднего возраста едут на севера - Тюмень, Томск, Уренгой, Якутия. Проблема в том, что [живет] молодая семья, он уезжает, ребенок маленький, жена дома одна, он там. Семьи распадаются. Участились случаи с летальными исходами - горят, тонут. На селе работы абсолютно никакой. Существует администрация сельская - специалисты, глава человек 15-16. Они обеспечены какой-то зарплатой» (муж., 40-50 лет).

Анализ полученных данных порождает вопросы, на которые пока никто из представителей власти не дал ответа: почему сельская миграция воспринимается как неизбежность, как объективный процесс, не поддающийся влиянию? Почему, например, не финансируется поддержка занятости в производственной сфере, тем более что число «бюджетных» рабочих мест во многих сельских советах превышает число таких мест в производстве? Какие социальные, экономические, производственные, культурные эффекты ожидаются в регионах в результате такого управления?

Как одну из разновидностей отходничества - исход, покидание своей земли, - вероятно, следует рассматривать миграцию молодежи из села, которая порой приобретает угрожающий размах (с учетом в целом небольшого числа молодых людей в сельских поселениях).

Исследование позволило выделить ряд особенностей профессионального образования, получаемого в сельских районах, и соответственно, получить представление о качестве трудовых ресурсов. Первое: учреждения профессионального обучения имеются не во всех районах области, что делает исход молодежи из родных мест вынужденным. Второе: набор профессий, по которым в них ведется обучение, часто не соответствует реальным потребностям районов и местных предприятий. Третье: профес- 
сии, по которым ведется обучение, востребованные местными работодателями, как правило, мало привлекают местную молодежь (о причинах - далее), так что проблема дефицита кадров сохраняется. Четвёртое: во многих профессиональных учебных заведениях набор сельскохозяйственных профессий ограничен небольшим перечнем. Пятое: работодатели, муниципалитеты, сельские советы, профессиональные учебные заведения слабо взаимодействуют между собой в вопросах создания рабочих мест, оплаты труда и привлечения молодежи на предприятия. Шестое: работодатели предлагают низкооплачиваемую работу, что вынуждает выпускников профессиональных учебных заведений уезжать в Новосибирск или близлежащие города и пригороды в поисках более привлекательных условий.

В результате мы получаем исход из сельских поселений молодежи, депрофессионализацию сельскохозяйственного производства, старение села, социокультурную деградацию.

Безусловно, тенденция исхода молодежи из села исторически имеет глубокие корни. Однако есть и критические точки (числовые значения) того или иного показателя, и причины отъезда, которые могут быть устранены. Так, чаще всего опрошенные называют следующие причины: а) отсутствие работы (64\% от числа ответивших); б) социально-статусная неудовлетворенность - «молодежь на селе не хочет работать», «мало выпускников школ, желающих получить образование в профтехучилищах» (64\% респондентов); в) материальная и социальная незащищенность (33\%).

Для того чтобы молодые люди не стремились уехать, у них должны быть не только работа и достойная зарплата, но и социальные перспективы: создание семьи из числа близких по уровню образования, культуры, образу жизни сверстников; профессиональное общение, карьерный рост внутри поселения или муниципального образования; межличностное общение и возможности воспитания детей, социальная перспектива и уверенность в нужности и востребованности обществом и государством сельского образа и уклада жизни, результатов сельского труда.

Следует отметить, что взрослое население поддерживает молодежь в её желании уехать из села. Фактически отсутствует активная позиция взрослого и старшего поколения побуждать молодежь и поддерживать её в стремлении стать самой работодателями на селе.

\section{Исследование показало, что «дело швах»}

В целом социально-экономическую ситуацию в сельских поселениях сами жители оценивают как почти безнадежную - социальная и производственная структура многих поселений достигла такой степени деградации, за которой следует их ликвидация в связи с обезлюживанием и запустением территорий и земель.

На территории 2/3 сельских поселений отсутствуют какиелибо субъекты агропромышленного производства. Единичные фермерские хозяйства и ОАО не способны абсорбировать имеющиеся трудовые ресурсы. В результате реальная безработица намного превышает официальные показатели. Более $20 \%$ населения не проживает постоянно на своих территориях, а обеспечивает занятость путем организации вахт и за счет отходничества. Причем в некоторых районах таковых от 30 до 46\% всего работоспособного населения. Как правило, это мужчины трудоспособного возраста, имеющие или получающие профессию.

Несмотря на господдержку сельхозпроизводства, устойчиво сохраняется «традиция» низкой зарплаты на селе как источника дешевой рабочей силы и, соответственно, низкого уровня жизни. Так, среднемесячная заработная плата в Новосибирской области на январь-февраль 2014 г. составила 25312,0 руб. [8], в то же время минимальная зарплата в сельском хозяйстве области установлена в размере 6200 руб.; фактическая чаще всего не выше.

На наш взгляд, четырехкратный разрыв в оплате труда не только депрессивный психологический фактор, но и социальный. Это показатель монетарной оценки значимости сельскохозяйственного труда обществом и органами государственного управления. Сформировалась устойчивая традиция платить очень маленькую зарплату труженикам села и поддерживать низкий уровень жизни для сохранения отходничества как источника дешевой рабочей силы в городе. Бедность стала рассматриваться как неотьемлемая характеристика сельского образа жизни.

Личные подсобные хозяйства (ЛПХ) также находятся в состоянии деградации и упадка. Если в 1994 г. поголовье крупного рогатого скота в личных подворьях Новосибирской области составляло 328,9 тыс. голов, то в 2014 г. - 117,6 тыс., поголовье свиней в 2002 г. - 265,6 тыс. голов, в 2014 г. - 131,1 тыс., поголовье овец в 1992 г. - 432 тыс. голов., в 2014 г. - 172,5 тыс. 
Таким образом, за счет имеющегося на данный момент в ЛПХ поголовья сельское население способно лишь отчасти удовлетворить только личные физиологические потребности и не получает дополнительные доходы для удовлетворения других потребностей даже на минимальном уровне.

Анализ социально-демографического состава населения сельских территорий свидетельствует о резких диспропорциях в его структуре. В поселениях превалирует население более старших возрастных групп. Свыше 50\% выпускников школ уезжают для поступления в учебные заведения в город. Одним из основных источников дохода являются государственные социальные пособия, что не может обеспечить ни удовлетворения потребностей жизнедеятельности, ни поддержания территорий на приемлемом уровне. Отмечается деградация качественного состава населения - снижение уровня образования, депрофессионализация, демотивация к труду, рост алкоголизма и наркомании, других девиаций. Отсутствие рынка труда с его альтернативами, возможностей к самообеспечению, выходящему за рамки поддержания физиологического существования, не оставляет сомнений в будущем аграрной экономики области и судьбе значительного числа сельских поселений.

Ответы руководителей муниципальных образований в ходе социологического исследования демонстрируют пассивность органов исполнительной власти в создании рабочих мест, привлечении и воспитании собственных (местных) работодателей, попытках построения новых фигураций отношений. Более того, нередко муниципальные власти в погоне за сиюминутной выгодой подрывают основы экономического благополучия своих граждан. Например, отдавая близлежащие пастбища под распашку фермерам, под строительство дач и т. д. и лишая тем самым население выпасов и возможности содержания скота на личных подворьях.

В отсутствие внятной стратегии комплексного социальноэкономического развития сельских территорий постоянно растущие объемы государственной поддержки сельхозпроизводства, затратные проекты инфраструктурного обустройства сельских территорий (строительство дорог, систем водоснабжения, газификация) - это путь в никуда. Допустимо ли вкладывать бюджетные средства в поддержание инфраструктуры поселений без параллельного создания современного сельскохозяйственного комплекса (в широком понимании) или переоборудования еще функционирующих?

В области есть значительное число поселений, в которые вложены средства и ресурсы по поддержанию бюджетных учреждений, дорог, инфраструктуры, проведению газопровода и т. п. Но в них и не было и нет рабочих мест, сельскохозяйственного производства. Не пора ли задать вопросы руководителям: «Почему нет работы? Чем занято население?».

А, может, сегодня селу «удобно» так существовать, и «удобно» управлять такими селами? Село как социальная жертва - это позиция, позволяющая винить всех вокруг, кроме самих себя. Но это и путь к дальнейшей социальной, производственной, социокультурной деградации, так как порождает не просто иждивенчество, но и социально-культурные деформации сознания, отношений, могут давать непрогнозируемые отрицательные эффекты.

\section{Новой аграрной политике - новую концепцию}

На наш взгляд, региону остро необходима новая эффективная программа социально-экономического развития сельских территорий, ориентированная прежде всего на сохранение сельского образа жизни.

По административно-территориальному делению и по определению муниципальные районы являются сельскими. Главный критерий сельской территории - наличие сельскохозяйственного производства и сельского уклада, образа жизни.

Сельский образ жизни - исторически сложившаяся форма индивидуальной и коллективной жизнедеятельности людей, составляющих специфическую социально-территориальную общность; социокультурную систему. Его специфика проявляется в социально-экономических, социально-психологических, культурных и природных условиях жизни: подчиненность труда ритмам и циклам года, неравномерность занятости в зависимости от сезонов года и низкая трудовая мобильность населения; индивидуально-коллективные и общинные способы производства, переработки и реализации сельскохозяйственной продукции и общественного блага; слитность труда и быта; элементы традиционной соседской общины в повседневном укладе; тип 
коммуникации, при котором доминируют доверительно личные взаимоотношения, коллективные обсуждения и действия, локальная ограниченность коммуникативных обменов; низкая социально-профессиональная и культурная дифференциация, высокая устойчивость исторически сложившихся форм труда, быта и досуга; ориентация на авторитетного, компетентного и заинтересованного в сельскохозяйственном производстве руководителя.

Многолетний период не просто упадка, а уничижения сельского уклада сегодня привел к массовой фрустрации и дезориентации сельских жителей. Ответы наших респондентов красноречиво показывают, что родители, учителя и все взрослое население сельских территорий, как правило, поддерживают молодежь в ее стремлении уехать из родных мест. Тем самым на первый план выходит одна из актуальнейших задач - работа с населением по воссозданию потребности в сельском образе жизни. Для этого требуются специальные программы социального оздоровления общества. Сельская идентичность, сельский образ жизни - это средства сохранения села и сельскохозяйственного потенциала.

При этом, в рассуждениях многих респондентов прослеживаются отголоски «социальной памяти села», которая не позволяет людям смириться с запустением родных земель, их бесхозностью и отсутствием реального общественно значимого дела. Многие люди, которые сегодня остаются жить в пустеющих селах, лишенных сельского хозяйства, неосознанно выполняют роль хранителей земли: «Пока мы на ней живем, чужсй на неё не придёт». Эта социально-охранная функция, а, может быть, и функция обеспечения национальной безопасности, обладает уникальной культурно-исторической и социально-антропологической силой.

Господствующие сегодня урбанистический, производственно-технический и бухгалтерский, балансовый подходы к развитию села такую силу выкорчевывают с корнем. Следует признать, что они вообще не отвечают современному состоянию села и требованиям стратегии его развития. Так, положительные статистические изменения каких-либо показателей практически не влияют на социально-психологический климат, в котором оказались жители сельских территорий. Нет ни прямой, ни опосредованной зависимости между финансированием отдельных агропромышленных комплексов и сельскохозяйственных предприятий и изменением положения дел в целом на селе и в сельском хозяйстве.

На наш взгляд, комплексное развитие села позволит обеспечить лишь переход от статистического планирования и управления к планированию и управлению изменениями. Под комплексом необходимо понимать такие целостные социальные единицы, как сельский образ жизни, сельский труженик, сельский житель, сельское поселение, сельский работодатель, сельский быт, сельская субкультура, социальная память и т. п. При этом все эти социальные единицы должны быть качественно операционализированы: не только и не столько через сухие цифры, сколько через мнения, отношения, чувства, желания жить на селе, видение своего будущего и будущего своих детей и внуков в сельском образе жизни, в желании трудиться на земле. Соответственно, для такого управления и планирования необходимо создание центра социально-экономического развития, в котором должны аккумулироваться имеющиеся данные социологических опросов.

\section{Концепция личных подворий}

На наш взгляд, экономической, организационной, идеологической основой для возрождения сельского уклада может послужить программа развития семейных ферм, личных подворий, развиваемая на принципах сельскохозяйственной, сбытовой кооперации. Она могла бы способствовать не только увеличению объемов сельскохозяйственной продукции, но и вовлечению сельского населения в процесс совместного производства - формированию кооперационных производственных связей, созданию хозяйственных союзов как одной из форм социальной организации и интеграции населения, преодолению известной диссипативности.

В СССР личные подворья обеспечивали до 80\% урожая картофеля, 60\% свинины, однако после распада страны этот сектор был практически исключен из системы государственной поддержки и перестал существовать как субъект производственно-экономических отношений. В среде экономистов наибольшую популярность приобрела точка зрения о низкой эффективности ЛПХ, на основании чего предпочтение в разработке мер государственной поддержки отрасли отдавалось крупным агропроизводствам. 
Однако себестоимость производства, рентабельность в хозяйствах населения оценить невозможно из-за отсутствия статистических данных по затратам труда. Феномен устойчивости личных хозяйств сельского населения связан прежде всего со спецификой жизненного уклада крестьян и зависит от производственного потенциала конкретной семьи, что игнорируется экономистами [9].

В советское время применялись различные формы поддержки и развития ЛПХ: постановка на откорм молодняка с последующей оплатой деньгами, талонами на приобретение дефицитных товаров; обеспечение кормами за счет коллективных хозяйств, льготирование стоимости приобретенного скота и т. п. Как показывают опросы, значительная часть населения помнит об этой деятельности и готова к обсуждению.

"Я считаю, что самое простое, чтобы людям дали возможность заниматься тем, чем они хотят, в деревне. У нас бы сейчас многие занялись бы скотом, но начального капитала нет, а кредит дают под 24\%. Люди бы здесь жили, оставались бы жить, потому что если это мое, значит, я пашу, чтобы получить какую-то прибыль, а если я работаю у “дяди” < ... [зачем] мне этот “дядя” нужен. Ребятишкам надо дать возможность работать, пришел он-хочу завести хозяйство, в деревне нужно для этого 300-400 тыс., дали ему лет на 10 и первые три года не лезьте к нему, у него появятся излишки, он придет и сам заплатит, и дать под 3-5\%, не больше. Деревни нужно поднимать, давать людям возможность работать. Наши местные власти не заинтересованы абсолютно в этом, пришел глава администрации, в первую очередь начали делить земли, которые остались. У меня племянник занимается растениеводством, глава пришел, начал отбирать землю, у него есть желание работать, так зачем отбивать желание» (муж., 30-49 лет, фермер).

На наш взгляд, эффективная программа поддержки личных подворий должна включать в себя различные формы и инструменты, разработанные на основе тщательного анализа имеющихся ресурсов, с учетом возможностей конкретных домохозяйств, локальной производственной инфраструктуры, логистических схем и возможностей сбыта конкретных видов и объемов продукции.

Важнейшим пунктом представляется подробная и хорошо продуманная разработка моделей, учитывающих состав и количество скота, возможности его содержания по указанным параметрам и т. д. К их обсуждению и отработке необходимо привлечь как специалистов-экономистов, так и представителей местных органов власти, начиная с низовых муниципальных образований, а также активно использовать имеющиеся наработки как советского периода, так и современной практики в отдельных регионах.

Впрочем, некоторые основные черты концепции развития личных подворий можно обозначить уже сейчас.

Поскольку продукция личных подворий может быть произведена только для удовлетворения потребностей местного рынка, это делает актуальным формирование кооперативных структур по сбору сырья и его переработке в малых объемах вблизи от производственной базы, а также поддержку и организацию внутрихозяйственной переработки.

С учетом наличия множества мелких производителей единственным механизмом организации сбыта продукции могут быть кооперативные ячейки, создаваемые на местах. Они позволяют разрозненным малым хозяйствам объединить свои ресурсы (трудовые, технические, земельные, денежные, транспортные, сбытовые и др.) для более эффективного использования. Ядром подобных кооперативных формирований могли бы выступить фермеры, осуществляющие производственную деятельность непосредственно на территории, мелкие и средние хозяйства акционерные общества. Кооперативное строительство могло бы происходить по инициативе и под руководством глав муниципальных образований и при полной ответственности за это глав сельских муниципальных районов.

Эта деятельность должна быть скоординирована с руководством городских округов и, прежде всего - Новосибирска, задача которых - обеспечить доступ продукции на местные рынки. С учетом опыта российских регионов (Татарстан, Омская область) это могут быть неформальные и формальные договоренности с торговыми сетями, переориентирование малых торговых предприятий, испытывающих в условиях кризиса существенные трудности, на сбыт продукции местных ЛПХ, поддержка строительства магазинов шаговой доступности и т. п.

Строительство малых перерабатывающих мощностей должно стать предметом специальной целевой программы. Наиболее эффективный путь для этого - реализация проектов 
переработки в рамках программы территорий опережающего развития на базе нескольких сельских муниципальных районов.

Эффективное развитие ЛПХ, а также фермерского сектора невозможно без развития кооперационных связей с сельскохозяйственными коммерческими организациями, фермерскими хозяйствами, а также без создания обслуживающих, сервисных, кредитных кооперативов, что возможно только при активной координирующей роли местного самоуправления во взаимодействии с органами государственной власти. Иными словами, главы сельских поселений должны будут решать локальные проблемы местного значения (организация коллективного труда по выпасу скота, установление норм предельной численности скота в конкретном поселении, маршрутов его гуртования, обеспечение водой, организация ветеринарных осмотров и оказания консультативной помощи специалистов, взаимодействие с контрагентами и др.) и выполнять функции главы кооперативного сообщества, членами которого являются жители конкретного поселения.

Один из возможных вариантов кооперации - создание владельцами ЛПХ обслуживающего или сервисного кооператива (в виде отдельного юрлица), который будет оказывать своим членам услуги по обработке земельных участков, закупке семян, переработке и сбыте продукции, заготовке и доставке кормов и т. д. Источниками формирования материально-технической базы такого кооператива могут быть имущественные паи их владельцев, денежные взносы пайщиков кооператива, другие источники.

На первом, наиболее сложном и ответственном этапе необходимы тщательный мониторинг и изучение возможностей домохозяйств, поиск партнеров, выстраивание кооперационных связей и отношений, решение инфраструктурных проблем, обеспечение ресурсами, организация совместной деятельности по производству и сбыту сельскохозяйственной продукции.

\section{В заключение}

На федеральном уровне существуют программы по сохранению самобытности и уклада жизни различных народов России. Подобную программу по сохранению сельской идентичности, сельского образа жизни необходимо принимать и по отношению к селу. В современной России есть успешные примеры реализации такого подхода, например, в Татарстане. Широко распространенные сегодня программы поддержки и создания агропромышленных комплексов - это важное направление, но оно не может заменить и компенсировать поддержку сельского уклада и образа жизни. Более того, разделение сельхозпроизводителей и представителей агропромышленного комплекса снижает заинтересованность сельских тружеников в производстве зерна, молока, мяса и т. п.

Речь должна идти не только о поддержке «эффективного собственника» в лице интегрированных агрохолдингов или крупных хозяйств, но и о развитии малых форм ведения хозяйства (семейно-фермерских, личного подворья и т. п.) на значительно большей территории области. Это решение лежит не только в экономической, но также и в политической плоскости, так как касается не только сохранения сельской идентичности и сельского образа жизни, но и сохранения территориальной целостности страны, благоустройства и благополучия населения всей области.

\section{Литература}

1. Лексин В., Швецов А. Региональная политика России: концепции, проблемы, решения // Российский экономический журнал. - 1993. № 9. - С. 51-52.

2. Иванов Н. П. Региональная экономическая политика: стратегия, инструментарий, эффективность (на материалах Ставропольского края): автореф. дисс. ... канд. экон. наук. - Волгоград, 2004. - С.17.

3. Бакитжанов A., Филин C. Управленческие аспекты инвестиционной политики (на примере Республики Казахстан) // Проблемы теории и практики управления. - 2001. - № 5.

4. Торлопов В. Социальное государство: сущность и генезис // Человек и труд. - 1998. - № 5.

5. Заключение Контрольно-счётной палаты Новосибирской области по результатам анализа соблюдения порядка и условий предоставления государственной поддержки сельскохозяйственного производства Новосибирской области; рассмотрено на заседании комитета по аграрной политике областного Законодательного собрания. URL: www. http:// kspnso.ru/news/2014 07 25/

6. URL: http://gefter.ru/archive/10587 (дата обращения: 29.12.2014). 7. Волков В.В. Влияние промысловой деятельности крестьян России конца XIX - начала XX века на развитие их хозяйства // ЭКО. - 2016. № 7. - C. $183-189$.

8. URL: http://www.nso.ru/page/2274

9. Смирнов В. Д. Особенности сельского хозяйства России // ЭКО. 2013. - № 5. - С. 23-28. 